\title{
En Torno a la Definición de Tortura: la Necesidad y Dificultad de Conceptualizar La Producción Ilimitada de Sufrimiento
}

\author{
Ignacio Mendiola \\ Doutor em Sociologia e professor no Departamento de Sociologia 2 da Universidade do País Basco. \\ Leioa, Biscaia. \\ E-mail: ignacio.mendiola@ehu.eus, https:/ / orcid.org/0000-0002-2703-5743
}

\section{INTRODUCCIÓN}

cercarse a la tortura es siempre un asunto complejo porque la
propia realidad de la tortura se encarga de trastocar las formas
reconocibles de lo humano precipitándose a un escenario que deja
atrás el sentido, el cuerpo, el lenguaje antes practicado (Scarry, 1985).
La tortura acomete una escisión radical en la cotidianidad, un aleja-
miento de las formas de estar y pensar a través de las cuales era posi-
ble conferir un cierto sentido, por precario que este pudiera ser, a la
propia vivencia de lo social. Y precisamente, por estar más allá de las
formas reconocibles de lo humano, por ser un quiebre que da lugar a
una animalización de lo humano en donde todo queda reducido a un
cuerpo doliente sustraído de empatía, la caracterización misma de la
tortura se torna extraordinariamente difícil: los límites se han borrado
y la tortura se despliega ahondando en la destrucción de lo humano.

La definición de la tortura siempre ha sido una cuestión espinosa. Los elementos a través de los cuales habría que recortar la diferencia de esta práctica punitiva no siempre están meridianamente claros y ello conlleva, en consecuencia, que el debate en torno a si un castigo es o no constitutivo de tortura dista mucho de tener una suerte de metodología nítida y compartida que habría de ayudar a elaborar decisiones consensuadas. Existe en la actualidad una definición, a la que luego aludiremos con más detalle, que está contenida en el texto de la Convención contra la tortura y otros tratos o penas crueles, inhumanos 
o degradantes (adoptada por la Asamblea de las Naciones Unidas en diciembre de 1984 y ratificada en junio de 1987), y que ha terminado por constituirse en una suerte de referencia obligada para acotar lo que se entiende por tortura. Sin embargo, la definición ahí propuesta contiene una serie de problemas que socavan su asunción acrítica.

Asumiendo la complejidad de esta tarea y sin ánimo de presentar un acercamiento que se presente como definitivo, el presente artículo pretende ofrecer una definición tentativa de tortura. Una vez explicitado el objetivo fundamental que estructura esta reflexión, creo necesario hacer una doble consideración inicial que ayuda a contextualizar la argumentación aquí expuesta. En primer lugar, aludir al hecho de que aun cuando el propósito que anima esta reflexión es fundamentalmente de corte analítico ello no supone, en modo alguno, desligar la reflexión misma de los usos que la noción de tortura ha tenido en diferentes ámbitos a lo largo de la historia o de sus contextos de aplicación en situaciones más o menos cercanas a nuestro presente. Más bien, y para clarificar en mayor medida la forma de proceder que aquí se seguirá, cabe decir que en el transcurso de la línea argumental se aludirán en momentos concretos a prácticas específicas de tortura, algo que se hará con el fin de que esas situaciones confieran un cierto espesor empírico al ejercicio de la propia conceptualización de la tortura. Así, el diálogo entre lo empírico y lo teórico, pese a estar más escorado hacia el plano teórico, acaba por dotar de una mayor consistencia al acercamiento teórico-conceptual que aquí se propone. Y, en segundo lugar, asumir que esa primacía conferida al plano teórico-conceptual no se entiende aquí desligada de una dimensión ético-política que inquiere críticamente en las condiciones de posibilidad de la tortura, en la producción de sufrimiento que se proyecta en mayor medida hacia unas determinadas subjetividades. Si bien esta consideración está de un modo u otro implícita a lo largo de la exposición, será abordada de un modo explícito en las conclusiones, cuando ya esté argumentado con mayor detalle el basamento desde el que se sugiere la reconfiguración del concepto de tortura.

Para todo ello, la reflexión propuesta se articula en tres momentos que si bien están diferenciados quedan entrelazados en el desarrollo de la argumentación. Así, en primer lugar, se realizarán unas breves clarificaciones previas de corte epistemológico en torno al ejercicio mismo de acometer una definición que servirán para contextualizar mejor nuestra propuesta. En segundo lugar, se analizará críticamente 
la mencionada definición de tortura recogida en la Convención contra la tortura y otros tratos o penas crueles, inhumanos o degradantes, aprobada por las Naciones Unidas; e igualmente, cabe acotar que en el desarrollo crítico de esa definición se avanzarán ya algunos aspectos que vienen a jugar un papel central en la aproximación que aquí se presenta. Por último, y en tercer lugar, se realizará una exposición detallada de un acercamiento conceptual a la noción de tortura sobre la base de tres dimensiones entrecruzadas que, como veremos, aluden a la captura, a lo inhabitable y a la inferioridad.

\section{SOBRE EL EJERCICIO DE DEFINIR}

El intento por trazar límites que permitan establecer demarcaciones más o menos nítidas ha funcionado a menudo como un poderoso mecanismo epistemológico desde el que proyectar la propia raíz etimológica de la definición a un ámbito específico. Definir - derivado de finis, allí donde la realidad aludida se termina y se diferencia de lo limítrofe quedaría así vinculado al ejercicio de trazar analíticamente un límite, una acotación por medio la cual una determinada realidad (vivencial, conceptual) se escinde del contexto en el que estaba inmersa, emergiendo así, como consecuencia de esa misma escisión, con un signo de diferencia. La definición crea un límite, una separación, un adentro y un afuera. Desde el límite mismo, en consecuencia, la diferencia se recorta y logra adquirir una especificidad que le permite contraponerse a otras realidades o circunstancias: lo que está dentro no es lo que permanece afuera. Esta tarea pudiera parecer sencilla, pero en el momento en que comencemos a pensar tanto en la realidad que queramos definir como en el propio debate analítico que se abre cuando la definición se piensa desde la imagen del límite trazado, los problemas comienzan a aparecer. Problemas epistemológicos y ontológicos.

Por una parte, la tarea de articular una definición debe pensarse desde las ruinas dejadas por una epistemología clásica en donde la idea de objetividad, en tanto que reflejo aproblemático de la realidad pensada, carece ya de potencia analítica (Woolgar, 1991). El límite que habría de proceder a la escisión de un determinado ámbito no es algo que nos pre-exista, algo que se justifica por sí mismo, sino que responde ineludiblemente a un proceso multidimensional que lo articula (o, en términos latourianos, lo objetiviza) de una determina forma con lo que la contingencia queda ya adherida a la definición misma: ese límite empleado acaso pudiera ser otro y, por tanto, todo límite es 
susceptible de ser problematizado. El límite habla de la realidad que se quiere acotar, pero también refleja los contextos sociohistóricos que inciden y atraviesan la propia actividad del pensar. La definición, aun cuando esta no lo haga explícito, lleva adherida la geografía en la que está inmersa, los espacios que habita, con lo que el conocimiento sólo puede darse y entenderse desde su carácter situado (Haraway, 1995). El límite que traza la definición, más que asumirse como punto de partida, puede ser visto como la huella de una geografía que merece ser repensada en sus procesos constitutivos, en los efectos que deja en las formas de pensar.

Por otra parte, y en lo referido a lo ontológico, la imagen del límite, decíamos, opera mediante un ejercicio de escisión, como si aquello que encontramos en lo que hemos encerrado dentro de la definición no pudiese ya ser detectado más allá de los márgenes con los que nos hemos dotado; o al menos no pudiese ser detectado en la forma en que ha sido definido. Y ello quizás sea así a veces. Pero en cualquier caso, esta aproximación deberá dialogar con la propia heterogeneidad constitutiva de lo social, con el hecho de que toda práctica social lleva igualmente la huella de otras realidades con las que no sólo se confronta (para enfatizar el semblante de su diferencia), sino que también inciden en la propia singularidad que pudieran llegar a tener. Afirmar que la heterogeneidad es constitutiva es tener presente que toda una trama de relaciones de diverso signo actúa como sustrato vehiculador de lo que se presenta como diferente y, por ello, la diferencia no puede soslayar la relación que la habita, la heterogeneidad que le hace ser lo que es. La imagen del límite corre el peligro de escindir algo que no es enteramente susceptible de ser escindido.

En esta sucinta aproximación a la definición nos confrontamos, por tanto, con una doble dimensión que no puede ser obviada: la construcción socio-histórica del límite (que introduce su contingencia) y la heterogeneidad propia de lo social (que cuestiona la imposibilidad de una cesura nítida). De esto no habría de deducirse, ciertamente, una posición paralizante a la hora de pensar la tarea de definir, como si esta fuera radicalmente imposible. Pero sí se deducen al menos dos cuestiones con meridiana claridad. La primera es que toda definición adviene como consecuencia de un proceso de objetivación de la realidad que lleva implícita la huella que deja la geografía de ese pensar. La 
segunda es que toda definición busca trazar una cierta especificidad pero teniendo presente que esa diferencia lleva la huella constitutiva de una heterogeneidad que la atraviesa y conforma.

Sobre la base de estas consideraciones previas podemos ya apercibirnos de que la cuestión del límite posee una especial relevancia en el tema que aquí nos ocupa y ello se plasma en un doble plano de actuación. Por una parte, y a nivel conceptual, es preciso trazar una distinción que nos permita recortar la diferencia susceptible de ser adscrita a la tortura porque no todo castigo puede ser lógicamente catalogado como tortura: la gravedad de lo que se imputa como tortura requiere el inicio de un procedimiento penal que establezca la naturaleza de los actos juzgados, la asunción de responsabilidades y los mecanismos compensatorios establecidos que la víctima habría de recibir. Por otra parte, y a un nivel experiencial, la tortura acontece a modo de una animalización de lo humano que rompe con los límites reconocidos y reconocibles: una suerte de trabajo experimental que indaga en lo que se puede hacer con un cuerpo, en la destrucción que aleja la corporalidad de lo que antes era precipitándose así el sujeto torturado en una realidad carente de marcos de referencia, de líneas de orientación.

La tarea que se impone, y que aquí es abordada, resulta del entrecruzamiento de estos dos niveles que orbitan, de forma diversa, en torno a la noción del límite: la necesidad de delimitar conceptualmente aquello que en su propio ejercicio se da como una ausencia de límites. La necesidad es irrenunciable si no queremos caer en un abuso injustificado de la noción de tortura, algo que ciertamente restaría fuerza a la propia denuncia de la tortura. Para encarar esta cuestión, la reflexión contenida en este artículo se adentra en esta exigencia de diferencia atribuida a la tortura retomado la intuición de Deleuze y Guattari cuando sugieren que "el concepto es una cuestión de articulación, de repartición, de intersección. Forma un todo, porque totaliza sus componentes, pero un todo fragmentario" (1997:24). Es decir, el concepto es un campo tensional, heterogéneo, en donde una serie de componentes interactúan componiendo "una encrucijada de problemas" que habrá de juntarse con otros conceptos que actúan en un mismo contexto social y teórico. El concepto, visto desde esta perspectiva, alude a "una heterogénesis, es decir, una ordenación de sus componentes por zonas de proximidad" (ibídem:24). 
Aquí, el límite no se borra pero queda ya desprovisto de una lógica dicotómica al tiempo que asume una heterogeneidad que en su propia imbricación viene a establecer la especificidad de lo que se está abordando. Y asume, igualmente, el carácter situado y contextual desde el cual se acomete la tarea de conceptualizar una determinada realidad. A partir de todo esto, proponemos articular una reflexión en donde la heterogénesis interna que recorre y posibilita una diferencia de la tortura habrá de estar marcada por tres componentes o lógicas constitutivas que quedarán referidas como la lógica de la captura, la lógica de la inhabitabilidad y la lógica de la otredad. Esta es la propuesta que aquí se expone y argumenta. Pero ello requiere, como ya se ha avanzado, un paso previo en el que se problematice la definición canónica existente sobre la tortura contenida en el artículo 1 del texto de la Convención contra la tortura y otros tratos o penas crueles, inhumanos o degradantes. Por ello, en el siguiente epígrafe diseccionaremos críticamente esa definición de tortura evidenciando sus carencias analíticas y desde ahí, a continuación, se expondrá en detalle la definición que aquí se defiende atendiendo a esa triple lógica que compone la heterogénesis subyacente a la tortura.

\section{ACERCAMIENTO CRÍTICO A LA DEFINICIÓN VIGENTE DE LA TORTURA}

Existe toda una serie de textos normativos de alcance internacional en los cuales, junto con la condena incondicional de la tortura, se han explicitado un conjunto de medidas que habrían de venir a establecer un modelo procedimiental para erradicar y hacer frente a esta práctica punitiva. Algunos de los más sobresalientes serían la Declaración Universal de Derechos Humanos (1948), el Pacto Internacional de Derechos Civiles y Políticos (1976) o la Declaración sobre la Protección de todas las Personas contra la Tortura y otros Tratos o Penas Crueles, Inhumanos o Degradantes (1975). Pero sobre estos tratados, en un clima de creciente preocupación por la cuestión de la tortura y en donde asociaciones internacionales en el campo de los derechos humanos, como Amnistía Internacional, ya habían iniciado campañas para denunciar esta cuestión, se levanta con un indudable sello diferencial el texto clave ya aludido que lleva por título Convención contra la tortura y otros tratos o penas crueles, inhumanos o degradantes. Este texto, acordado en la Asamblea de las Naciones Unidas en 1984 y ratificado en 1987, viene a convertirse en la referencia central en el ámbito internacional a la hora de abordar la tortura, toda vez que ahí se explicitan, de un modo ya muy pormenorizado, los compromisos que los Estados firmantes se 
ven obligados a tomar con el fin de perseguir la práctica de la tortura ya sea en su propio Estado u otro, al tiempo que se exigen medidas reparadoras para las víctimas. No vamos a entrar ahora en la génesis de ese texto (Burgers y Danelius, 1988), o en el análisis detallado de las medidas ahí contenidas y las posibles críticas que algunos de sus artículos pudieran suscitar (Parry, 2010; Rivera, 2006). Nos interesa, en consonancia con el objetivo ya avanzado, ahondar en la propia definición de la tortura que ahí se propone, en el modo en que viene a ser categorizada y que presenta una indudable novedad e importancia tanto porque los anteriores textos normativos adolecían de una definición explícita y fundamentada como por el hecho de que esa definición viene a constituirse en el marco compartido de análisis con el que se dotan los países firmantes. Es necesario, por tanto, recoger en su propia literalidad la definición de tortura consensuada:

A los efectos de la presente Convención, se entenderá por el término "tortura"
todo acto por el cual se inflija intencionadamente a una persona dolores o
sufrimientos graves, ya sean físicos o mentales, con el fin de obtener de ella
o de un tercero información o una confesión, de castigarla por un acto que
haya cometido, o se sospeche que ha cometido, o de intimidar o coaccionar
a esa persona o a otras, o por cualquier razón basada en cualquier tipo de
discriminación, cuando dichos dolores o sufrimientos sean infligidos por
un funcionario público u otra persona en el ejercicio de funciones públicas, a
instigación suya, o con su consentimiento o aquiescencia. No se considerarán
torturas los dolores o sufrimientos que sean consecuencia únicamente de
sanciones legítimas o que sean inherentes o incidentales a éstas (artículo 1).

Este acercamiento a la tortura presenta una serie de ejes constitutivos que aluden a su contexto (ligado al poder estatal), al carácter específico a través del cual se vehicula un castigo (desde la intencionalidad) y a la naturaleza del mismo (daños graves). La concurrencia de los tres ejes indicados vendría entonces a componer una realidad determinada en donde se despliega un hacer punitivo que cabe nominar, como resultado del anudamiento de los tres ejes mencionados, en términos de tortura. Pero estos tres ejes - ligazón con el poder estatal, intencionalidad y daños graves - articulan una realidad que está lejos de poder ser leída de un modo unívoco. Conviene, por ello, ahondar en los problemas que cada eje suscita para, a partir de ahí, articular nuestra propuesta. 


\section{El contexto estatal de la tortura}

La clarificación contextual de la tortura merece ser reseñada en primer lugar, ya que al hacerlo queda circunscrito su ámbito de actuación, delimitando así un campo que se caracteriza por los actos "infligidos por un funcionario público u otra persona en el ejercicio de funciones públicas, a instigación suya, o con su consentimiento o aquiescencia". Afirmar el nexo ineludible con el aparato estatal (Anitua y Quiros, 2013) evidencia ya que la tortura no puede darse al margen del área de influencia del entramado punitivo del Estado en cualquiera de sus manifestaciones: la tortura nos confronta con el hacer del Estado a través del ejercicio concreto llevado a cabo por algunas de sus instancias; esto es, no hay tortura al margen de la actuación realizada o promovida por elementos del aparato estatal. Esta clarificación contextual establece, en consecuencia, una limitación: determina que el agente conductor de la tortura está asociado a los cuerpos funcionariales del estado, siendo estos fundamentalmente, en el campo que aquí nos ocupa, los integrantes de los cuerpos militares, policiales o funcionarios de prisiones con los que se dota el entramado estatal para gestionar el orden y la seguridad así como el cumplimento de las sentencias punitivas.

Pero esta delimitación es susceptible de ser complejizada. Tal y como se recoge en la propia definición de las Naciones Unidas, el ejercicio mismo del castigo no precisa que se ha llevado a cabo únicamente por personas que son funcionarias públicas dado que ahí se alude al consentimiento o la aquiescencia que las mismas podrían mostrar. Es decir, puede haber un conocimiento por parte de determinadas instancias del entramado público-estatal de que se está produciendo una situación que comporta "daños graves" a una persona o colectivo y se omite poner remedio a esa situación. La tortura no aludiría, en consecuencia, únicamente a un hacer directo cuanto también a un dejar hacer, con lo que la geografía de la tortura se expande allí donde el Estado tiene conocimiento de "daños graves" y viene a cometer el delito de tortura no por acción sino por omisión (De la Cuesta Azurmendi, 1990).

Dos ejemplos bastan para ver la amplitud que aquí se abre. Por una parte, y enunciado sucintamente, se encuentran las prácticas de violencia de género ritualizadas que permanecen en determinados contextos sin que el Estado haga nada por impedirlas (Redress y Amnistía Internacional, 2011; Peters, 2006). Por otra parte, Manfred Nowak (2009) y Juan E. Méndez (2013), ex-relatores especiales de las Naciones Unidas 
para la tortura, han aludido en informes suyos a la situación que se abre con los recortes sociosanitarios y la influencia que ello tiene en la interrupción del tratamiento médico a determinados pacientes aquejados de patologías graves, lo que supondría producir sufrimientos en una escala creciente hasta acabar con la muerte. En esta situación, a juicio de Nowak, "la denegación de hecho del acceso al alivio del dolor, si provoca dolor y sufrimiento graves, constituye trato o pena cruel, inhumano o degradante" (2009, parágrafo 72) y, por su parte, Méndez afirma que

no todos los casos en que una persona sufre dolor intenso pero no tiene acceso al tratamiento adecuado constituirán tratos o penas crueles, inhumanos o degradantes. Ello solo sucederá cuando el sufrimiento sea grave y cumpla los requisitos mínimos aplicables en cuanto a la prohibición de la tortura y los malos tratos; cuando el Estado tenga, o deba tener, conocimiento del sufrimiento, incluso cuando no se ofrezca un tratamiento adecuado; y cuando el Gobierno no haya adoptado todas las medidas razonables para proteger la integridad física y mental de las personas (2013, parágrafo 54).

Lo que estos casos nos muestran, el primero referido a una geografía propia de países del sur y el segundo, que responde también a un contexto occidental y que ha tenido una mayor incidencia en un escenario de fuerte crisis económica, es la necesidad de poner en relación el hacer concreto y directo de la tortura con un dejar hacer que produce dolor y sufrimiento.

Ciertamente, hay todo un imaginario de la tortura que la vincula especialmente con lo que ocurre en la geografía de privación de libertad gestionada por el Estado (una celda o una cárcel, por ejemplo) pero esto, aun siendo parte constitutiva del espacio en donde opera la tortura, no agota el escenario en donde esta se despliega. La vinculación del Estado con la tortura exige rastrear la propia actividad de las instancias estatales allí donde estas tienen lugar y se despliegan. Y supone, en definitiva, trascender una visión que individualiza la tortura en la figura del torturador para adentrase en una etnografía de las prácticas estatales (Agier, 2015; Ong, 2010) asociadas a la producción de dolor y sufrimiento (Avelar, 2004; Das, 2008; Dayan, 2007; Wisnewski, 2010). Esta aproximación está contenida en las clarificadoras palabras de Mauro Palma, ex-presidente del Comité Europeo para la Prevención de la Tortura, cuando afirma que en la persecución de la tortura es necesario trascender la geografía formalizada de privación de libertad 
ya que esa privación existe "cada vez que un sujeto es retenido en un lugar por parte de una autoridad pública - y, por lo tanto, no es libre de dejarlo voluntariamente -, independientemente del hecho de que tal lugar sea formalmente definido y previsto como celda $u$ otro lugar de posible alojamiento (el furgón que acompaña a una persona a una comisaría es lugar de privación de libertad)" (2010:89). Es decir, hay una geografía de privación de libertad institucionalizada pero la retención, previa a la tortura, pudiera darse en cualquier espacio (en el espacio público de la calle, en el doméstico, en las zonas fronterizas, en las prácticas de deportación de migrantes, etc.) con lo que la geografía de la tortura se abre más allá de los límites geográficos institucionales.

Mantendremos así, como criterio inexcusable de nuestra propuesta, la vinculación de la tortura con el aparato público-estatal, pero bajo la exigencia de tener presente que esa vinculación se abre a un doble plano en donde hay que imbricar, por una parte, el hacer y el dejar hacer $y$, por otra, tanto las geografías formalizadas de privación de libertad como cualquier geografía en la que el aparato público-estatal, por acción u omisión, genera una retención o situación propiciadora de un dolor irrestricto.

\section{La tortura como una práctica punitiva intencional}

En la definición de las Naciones Unidas se asume que la tortura puede tener propósitos diversos al designar un castigo que se inflige a una persona para obtener "información o una confesión, de castigarla por un acto que haya cometido, o se sospeche que ha cometido, o de intimidar o coaccionar a esa persona o a otras, o por cualquier razón basada en cualquier tipo de discriminación", pero lo que se enfatiza, como criterio clave de la definición, es que esa diversidad de propósitos implementados mediante castigos físicos o mentales, se puede englobar en un acto que "se inflija intencionadamente". La diferencia, en consecuencia, no se recorta por la modalidad del castigo ni por la motivación que lo desencadena sino por el hecho decisivo de que la tortura acontece como resultado de un acto intencional que se propone hacer daño. La consecuencia primera y más evidente de este énfasis puesto en la intencionalidad es la primacía que se le confiere a la figura concreta de un torturador, erigida en el actor principal que produce un daño a otra persona como consecuencia de una volición contenida en sus propios actos. 
La tortura es lo que alguien hace a otra persona con el firme propósito de querer hacer daño y, por ello, la tortura no es algo que se desprenda a modo de una consecuencia no intencionada de la acción sino que está incrustada en el núcleo mismo de aquello que articula y da forma a un determinado hacer. Más allá de las técnicas empleadas y de la finalidad establecida, el torturador asume el sufrimiento del otro en su proceder, lo hace suyo y lo convierte en el elemento vehiculador de su relación con la persona torturada. Bajo el prisma de la intencionalidad, en consecuencia, toda la problemática de la tortura queda, en gran medida, circunscrita a los actos concretos que el torturador ejercita sobre el cuerpo del torturado. No se trata, en modo alguno, de negar que la intencionalidad sea ajena a la tortura: puede haber ciertamente un querer-hacer-daño que funciona a contracorriente de cualquier gesto de empatía que vendría a socavar la continuación misma de la tortura, e incluso un disfrute en ese hacer daño que se transmuta en lo que Nietzsche (1981) pensó bajo la figura del goce de hacer sufrir en tanto que parte constitutiva de la pena impuesta. Pero este énfasis puesto en la intencionalidad arrastra un doble problema que es preciso encarar.

El primero es que el ejercicio de la tortura puede ser el resultado de una práctica de castigo incorporada en el sistema punitivo de un determinado Estado. De ser así, la tortura no remite ya a un sujeto concreto que la activa cuanto a la implementación rutinaria, habitualizada, cabría decir anónima (en el sentido de que la gestionan y supervisan unos determinados funcionarios pero estos podrían ser cualquiera en ese cuerpo de seguridad) y legalizada de un proceder que acaba ocasionando daño y sufrimiento a la persona que recibe la pena. De la figura individualizada del torturador pasamos al dispositivo específico de castigo (en el sentido foucaultiano del término dispositivo) que se proyecta sobre los cuerpos castigados. Un ejemplo puede valer aquí para ilustrar esta idea: el régimen de aislamiento que se impone en la cárcel (lo que se ha venido en llamar la "cárcel dentro de la cárcel") y que permite la reclusión solitaria del preso en una celda durante un período de tiempo que varía según los países pero que puede ir de 20 horas al día a la totalidad del día. En este caso, el aislamiento cumplimenta un desgajamiento radical de la persona de cualquier rastro de cotidianidad mínimamente vivible y portadora de sentidos: el mundo desaparece y el recluso queda encerrado en un espacio mínimo, en una soledad impuesta, viviendo una vida que es la negación misma de la vida y en donde su propia corporalidad lo llena todo. El ya citado exrelator especial sobre la tortura 
de las Naciones Unidas, Juan E. Méndez (2011), elaboró un informe en este sentido aduciendo, sobre la base de numerosas investigaciones ya realizadas, que cuando la situación de aislamiento se prolonga más allá de 15 días, lo que vendría a catalogarse como "régimen de aislamiento prolongado", los efectos sobre las personas adquieren ya una importancia muy reseñable que puede llegar a ser irreversible. Las palabras de Pilar Calveiro sobre su estudio del régimen de aislamiento en México sirven aquí como condensación de toda una forma de hacer que, si bien busca su legitimación en la seguridad del espacio carcelario y en el castigo añadido que unas determinadas personas supuestamente habrían de merecer, viene a constituirse en una práctica habitualizada de tortura:

El poder visibiliza e invade tecnológicamente la privacidad hasta los espacios más íntimos, destruyéndola. Lesiona así la propia condición de la persona y la lleva al desquiciamiento psíquico. Opera por un vaciamiento del sujeto, en tanto tal, reduciéndolo a la estricta condición de cuerpo biológico en estado vegetativo; un cuerpo que respira, pero que no "vive"; un cuerpo que permanece conectado al "respirador" por una decisión estatal perversa que, al mismo tiempo, pugna por mantenerlo vacío, desconectado de la conciencia. Es puro biopoder (2010:374-375).

Añadir que las investigaciones llevadas a cabo en España por Ríos y Cabrera (2002) en torno al régimen Fichero de Internos de Especial Seguimiento (FIES), poniendo de relieve las violencias físicas y simbólicas que ahí se despliegan, vienen a corroborar la ligazón de la tortura con el régimen de aislamiento.

El segundo problema que quisiéramos mencionar en relación a la intencionalidad está ya contenido en lo que arriba se ha firmado y puede expresarse de un modo más sucinto: el torturador es un sujeto que forma parte del contexto político-punitivo en el cual se ejerce la tortura y aun cuando quepa aludir a su individualidad específica y a sus actos concretos, no es del todo escindible del contexto en el que está inmerso, de las prácticas que ahí tienen lugar, de las narrativas que se construyen sobre unas subjetividades leídas en clave de desprecio que anticipa la posibilidad del daño proyectado hacia ellas. La intencionalidad enfatiza el acto de un sujeto concreto y, con ello, se corre el riesgo de descontextualizar tanto a ese sujeto como a su acto, desgajándolo de las condiciones de posibilidad que permiten la aparición de la tortura, como si esta, en definitiva, dependiera de la libre voluntad de un sujeto que se excede en sus funciones. En estas líneas se incide, por el 
contrario, en que la tortura remite a una práctica (más allá de un acto puntual) que emerge en un determinado contexto político-punitivo, con lo que en su propio ejercicio cabe aprehender algo que desborda al sujeto concreto que la activa: antes de la figura del torturador están los espacios de producción de tortura, con sus técnicas, sus racionalidades, sus relatos. El límite que traza la intencionalidad es demasiado estrecho, palidece ante la constatación de que la tortura es, antes que nada, un crimen propio de la geografía de Estado.

\section{LA TORTURA Y LOS DAÑOS GRAVES}

El tercer eje que estructura la definición de tortura se refiere a aquello que se produce como consecuencia de ese hacer intencional y que, según el texto de la Convención, cabe aprehender como la imposición de "dolores o sufrimientos graves". Dejamos para el siguiente epígrafe la reflexión en torno a la producción de dolor o sufrimiento (categorías que no son ciertamente unívocas) para centrarnos ahora en ese último criterio diferencial que viene marcado por la gravedad atribuida al dolor o sufrimiento.

No habría problema en acordar que la tortura, como antes se decía, es una situación límite, de especial trascendencia, marcada por una destrucción de los fundamentos ontológicos que caracterizan a lo humano toda vez que la persona torturada se ve sometida a una sustracción de su contexto vital y a una confrontación sin protección alguna frente a un entramado de poder que, reduciéndolo a una corporalidad doliente, se abalanza sobre el sujeto (Sofsky, 2006). La tortura sería la pena punitiva por excelencia y susceptible, por ello, de ser desligada de otro tipo de castigos que no comportarían, en la persona que los sufre, ese daño corporal tan intenso. A tales efectos se entiende que hay un gradiente en el daño causado, lo que queda recogido en el artículo 16 del texto de la Convención de las Naciones Unidas:

“Todo Estado Parte se comprometerá a prohibir en cualquier territorio bajo su jurisdicción otros actos que constituyan tratos o penas crueles, inhumanos o degradantes y que no lleguen a ser tortura tal como se define en el artículo 1 , cuando esos actos sean cometidos por un funcionario público u otra persona que actúe en el ejercicio de funciones oficiales, o por instigación o con el consentimiento o la aquiescencia de tal funcionario o persona". La tortura es aquello que irrumpe cuando se supera el campo punitivo contenido en la amalgama de "tratos o penas crueles, inhumanos o degradantes". 
Pero este planteamiento, ciertamente, no es ajeno al problema evidente de poder dictaminar de un modo nítido cuestiones tales como cuándo empieza algo que cabría denominar como un dolor y sufrimiento grave, las conexiones de la tortura con esa trama de "tratos o penas crueles, inhumanos o degradantes", el hecho de que hay un componente subjetivo en el dolor que habría de comportar en las personas torturadas diferentes apreciaciones en torno a la gravedad de lo sufrido o, por último, constatar que en la propia tortura cabría aludir a diferentes gradientes de intensidad en función de la tecnología empleada.

Conviene recordar aquí la apreciación efectuada por De la Cuesta Azurmendi en este aspecto cuando afirma que:

sería preferible un mayor esfuerzo de concreción de los comportamientos constitutivos de tortura y, prescindiendo de la referencia a los dolores o sufrimientos constitutivos de tortura, optar por una configuración típica del delito de tortura como delito de mera actividad (y no de resultado) centrado en el empleo, con determinados fines, de medios violentos o intimidatorios de cierta intensidad (criterio éste difícil de evitar si no se quiere llegar a una excesiva ampliación del concepto de tortura) (1990:43-44).

La alusión a una "cierta intensidad" quizás no venga a ser más que una débil redefinición de la espinosa cuestión de la gravedad asociada al daño y sufrimiento. No obstante, creemos relevante recoger la intuición de que la tortura ha de quedar catalogada como "delito de mera actividad", en el sentido de que remite a una práctica concreta que ha de ser pensada en sí misma, en lo que comporta, en el escenario que abre, más allá de toda una serie de peculiaridades que podrían quedar asociadas a su espacialidad, duración o tecnología: a la persona torturada se le puede tocar o no, se le puede aplicar un castigo corporal asociado a los hábitos que conforman el sustrato simbólico de su subjetividad (como sucede con las personas musulmanas torturadas en función de los hábitos que marcan su relación con la sexualidad), se le puede amenazar con un tormento que esté asociado a los miedos más íntimos (como en la imprescindible novela 1984 de Orwell), pero toda esta diversidad procedimental no debería ser la antesala para transitar por una casuística en la que buscar aquello que habría de determinar el elemento diferencial de la gravedad. Mantendremos aquí, por el contrario, que la tortura es una práctica que abre una realidad específica susceptible de ser pensada (y definida) atendiendo a una serie de dimensiones (desarrolladas en el siguiente epígrafe) que 
la atraviesan y que vienen a conformar la arquitectura (más allá de las formas que luego pudiera adoptar) de una práctica punitiva que cabe nominar como tortura.

En este sentido, para concluir este epígrafe, cabe apostillar que ni la intencionalidad ni la gravedad constituyen, a nuestro juicio, elementos constitutivos de esas dimensiones; son rasgos que lógicamente pueden estar presentes pero no ayudan a categorizar adecuadamente esta práctica político-punitiva. La intencionalidad corre el peligro de diluir el contexto político-punitivo en una figura concreta que se excede, como si el problema de la tortura fuera únicamente un problema de torturadores; la gravedad, por su parte, reproduce una mirada que se aleja de lo que supone la disección misma de una situación de tortura para subrayar ese límite esquivo que busca en una escala de dolor una diferencia agravante que no es susceptible de encontrarse en otro tipo de castigos.

Sí cabe, como anteriormente hemos mantenido, retener de la definición propuesta en el texto de la Convención, la ligazón con el aparato estatal, aun cuando como ya hayamos sugerido, esa ligazón se complejiza al aludir tanto al hacer como al dejar hacer, pero esto, sobra decirlo, no es tanto un problema de la definición de la tortura cuanto un rasgo inherente de la geografía multidimensional y abigarrada del poder estatal que es preciso no obviar. Desde ahí proseguimos la tarea de repensar la tortura pero acompañados de otros elementos que nos permitan dirimir con mayor finura la especificidad de esta práctica.

\section{RECONCEPTUALIZANDO LA TORTURA}

Tal y como se ha sugerido en la Introducción, la aproximación a la tortura que aquí se va a realizar pasa por entrelazar tres dimensiones que actúan conjuntamente, articulando, en virtud de ese entrecruzamiento, una situación que porta en su seno una diferencia. En este sentido, el acercamiento que aquí se realiza no busca tanto enfatizar el sujeto concreto que la desencadena (el torturador desligado del contexto que le posibilita) ni los efectos que pudiera desencadenar (el gradiente de sufrimiento que la tortura hubiera de producir), cuanto indagar en la arquitectura simbólico-material que produce una práctica ligada al entramado punitivo del Estado. Para ello, retoma elementos que ya han salido en el anterior epígrafe pero que aparecen ahora en el marco articulado de nuestra propuesta y en esas remisiones mutuas que se desatan entre 
las tres dimensiones empleadas: la captura (referida a la conexión con el entramado público-estatal), lo inhabitable (referido a una situación atravesada por el dolor y el sufrimiento) y la otredad (referida a la subjetividad que sufre la tortura). Veámoslo con más detalle.

\section{La dimensión de la captura}

Podemos acercarnos a esta primera dimensión de la tortura aludiendo a una sugerente imagen que Canetti expone en su libro Masa y Poder: "Es natural encontrar el acto decisivo del poder allí donde desde siempre es más notorio, tanto entre los animales como entre los hombres: precisamente en el agarrar" (1987:202; subrayado en el original). El poder, en su forma más extrema, donde se muestra y despliega con toda su potencial virulencia, acontece en el momento en que agarra, que captura a una presa y le posiciona en un espacio en donde todo queda ya reglado y conformado por lo que dispone quien ha agarrado. En esta situación, apunta Canetti, "la mano que ya no suelta se convierte en el símbolo propiamente dicho del poder" (ibídem:200).

La tortura presupone una captura, una mano que agarra, que detiene y retiene. Un ejercicio de poder que, si atendemos a la formulación foucaultiana, se aleja indefectiblemente del contexto de relaciones de poder que actúan sobre el potencial campo de posibilidades de los sujetos con el fin de "conducir las conductas", para proyectarse a un ejercicio de violencia en donde el margen de actuación queda erradicado. En palabras del propio Foucault: "Una relación de violencia o bien actúa sobre un cuerpo o bien sobre cosas: fuerza, subyuga, destruye: clausura todas las posibilidades" (2001:431). La noción de violencia es ciertamente compleja (Laurie y Shaw, 2018; ScheperHughes y Bourgois, 2004; Zizek, 2009) en la medida en que opera sobre diferentes niveles (estructurales y cotidianos, materiales y simbólicos) pero en esta sucinta aproximación creemos necesario tener presente un enfoque que más que asentar el ejercicio de la violencia en aquella subjetividad concreta que la implementa reubica el hacer violento en tanto que elemento constitutivo de un ordenamiento social que se proyecta sobre unos cuerpos; con ello no pretendemos borrar el rostro de esa subjetividad específica que inflige violencia, cuanto posicionar esa subjetividad en toda la trama de espacios y relaciones que producen las condiciones de posibilidad para un hacer violento: para que haya torturadores tiene que haber espacios que posibilitan la tortura, tiene que haber una producción social de la tortura. 
Lógicamente, la idea de captura puede ser tematizada en otros sentidos, pero el modo en que la reapropiamos aquí, sobre la base de la intuición de Canetti, remite a una práctica que se acomete como un acto de autoridad ligado al poder estatal que se precipita hacia la violencia: la tortura presupone una captura que funciona a modo de una suerte de desgajamiento radical de lo cotidiano que borra cualquier asomo de protección, de salvaguarda que los derechos recogidos en el ordenamiento vigente habrían de comportar. Lo relevante, en consecuencia, es poner de manifiesto el entramado de racionalidades y tecnologías de poder que dan forma a los procesos de captura, subrayando, tal y como sugieren Deleuze y Guattari que en la captura, cuando esta se vincula a la policía del Estado o a la violencia del derecho, se implementa un derecho de captura por medio del cual "la captura contribuye a crear lo que captura" (1988:454). La captura opera, entonces, como un vector en movimiento que inmoviliza al sujeto capturado, le coarta su libertad de acción y le despoja radicalmente de los derechos vigentes a los que se podría acoger la persona capturada. La violencia se convierte así en el envoltorio de una captura que, al margen de los modos en las que esta pueda tener lugar, opera mediante una erradicación del amparo y una supresión del tiempo reconocible, confrontando así al sujeto capturado y encerrado en su propia corporalidad, con una autoridad que se arroga la posibilidad de actuar impunemente con ese cuerpo indefenso.

Sobre lo dicho en el anterior epígrafe es necesario tener presente la heterogeneidad de formas a través de las cuales puede acontecer la tortura (las técnicas empleadas, la geografía en la que se proyecta, la duración de la misma, su vinculación a un hacer concreto o a un dejarhacer que hay que rastrear en sus procesos de conformación) pero lo relevante es que, más allá de esa heterogeneidad, la tortura irrumpe a modo de una captura que desgaja, aísla y retiene. La tortura acomete una inclusión que excluye radicalmente a quien ha quedado incluido, buscando igualmente socavar la posibilidad misma de la resistencia. Retomando la poderosa imagen desarrollada por Agamben, cabría decir que el torturado es el sujeto sumido en el bando (un sujeto abandonado) a través de una exclusión que prefigura una animalización de la existencia en la que se quiebra el ejercicio de una vida cualificada y digna de ser vivida: "Lo que ha sido puesto en bando es entregado a la propia separación y, al mismo tiempo, consignado a la merced de quien lo abandona, excluido e incluido, apartado y apresado a la vez" (Agamben, 1998:142). Un sujeto reducido a su propia corporalidad, desgajado de su mundo, abandonado (cabría decir capturado) 
a la impunidad de lo que el poder soberano disponga. La captura funciona a modo de una exclusión incluyente que es necesario etnografiar para poner de manifiesto el modo específico en que irrumpe y se despliega; algo que, por otra parte, permitiría superar las carencias del planteamiento de Agamben alejándonos de la supuesta pasividad de quien queda sometido al bando (incluso en la tortura, pese a todas las dificultades existentes, pueden activarse estrategias de resistencia) y del sesgo homogeneizante y teleológico que Agamben desliza en su análisis (mostrando aquellos posicionamientos socio-estructurales que facilitan o no la irrupción del bando).

Lo relevante, para concluir, es que esa captura, en su ligazón con el (dejar) hacer estatal puede llevar en su propio ejercicio la huella de un discurso que se asienta en la excepcionalidad, en el hecho de que para mantener un determinado orden en ocasiones es preciso acometer una particular estrategia de defensa inmunitaria (Esposito, 2005) con respecto a una serie de peligros y amenazas. La excepcionalidad nombra así una forma de proceder por medio de la cual se asume que en la protección de dicho orden (la democracia, un estilo de vida, unas garantías jurídicas para el conjunto de la población etc.), ese mismo orden puede ser suspendido con el fin de adoptar una serie de medidas fuera de lo común (la tortura a los sospechosos de terrorismo para extraer información, la negación de derechos a aquellos migrantes que vendrían a poner en peligro una forma de vida) que permiten garantizar procedimientos de defensa y la eventual recuperación del orden amenazado. Esta excepcionalidad, impregnada cada vez más de un discurso securitario (Balzacq et al., 2010; Bigo, 2008; Feldman, 2004; Neocleous, 2014), que no nombra necesariamente un momento puntual susceptible de ser revertido cuanto un engranaje políticosimbólico-jurídico que acaba por incrustarse en el ordenamiento de lo social, viene a poner de manifiesto de nuevo la compleja relación existente entre violencia y derecho, ya apuntada por Benjamin (1991) y desarrollada con precisión por Esposito (2005), en la medida en que el derecho, en el ámbito que aquí nos compete, puede habilitar prácticas violentas que colindan con la permisividad hacia la tortura. Esto puede verse en circunstancias tales como el ya mencionado aislamiento penitenciario, la situación de detención incomunicada para unos determinados presos acusados de terrorismo antes de pasar a disposición judicial, la imposición de la pena de muerte (Garland, 2013), las detenciones ilegales bajo el pretexto de la seguridad estatal (Portilla, 2009), la denegación de auxilio hacia los migrantes en situa- 
ción de peligro en altamar (Heller y Pezzani, 2014), o el ataque por medio de drones para eliminar con una supuesta precisión quirúrgica sujetos terroristas (Shaw, 2016).

Las anteriores situaciones, en consonancia con lo ya dicho en torno a la necesidad de etnografiar las prácticas estatales en su conexión con la producción de sufrimiento, irrumpen como formas disímiles de captura en donde ya no es imprescindible la presencia de una geografía de privación de libertad formalizada cuanto la activación de una lógica del bando que quiebra la posibilidad de vivir una vida vivible, una vida en la cual se pueda reconocer una forma de vida digna. Por ello, lo relevante para poder hablar de la existencia de una práctica de tortura, será rastrear la conexión de esa captura, de esa lógica del bando, con el hacer directo o indirecto del entramado público-estatal y mostrar, acto seguido, la negación radical de la vida que ahí se puede suscitar (lo que será abordado en el siguiente epígrafe).

En definitiva, la imbricación de la tortura con la excepcionalidad y lo securitario (algo evidente, por ejemplo, en el trascurso de la llamada guerra contra el terror), refuerza la necesidad de transcender la imagen de la intencionalidad que prioriza la figura individualizada del torturador para reubicarla en tanto que parte integrante de los procesos de captura que se dan por parte del Estado: en el fondo de la tortura está la captura político-punitiva que la desencadena, unas formas de hacer, de decir, de pensar, que preexisten al torturador, que hacen al torturador.

\section{La dimensión de lo inhabitable}

La captura que desencadena la tortura es la captura que altera la estructura misma de lo cotidiano, el contexto situacional en el que se está inmerso, las referencias que se tenían, los espacios y tiempos practicados, las tramas de ayuda, cuidado y solidaridad que permitían encarar los problemas que pudieran surgir. La tortura nos arranca de lo cotidiano, aísla, individualiza. En el relato de Strejilevich esto se enuncia con una contundencia irrebatible: "El espacio se deshace entre los pies" (1997:16). A la persona torturada se le sustrae del espacio habitado, pero no sólo en el sentido más banal de que uno deja de transitar por los espacios cotidianos, de que se le pudiera trasladar a otro lugar, o de que el lugar en el que se está ha quedado radicalmente reconfigurado por el escenario que desencadena y abre la captura. Al torturado se le sustrae, y esto lo más radical, de las formas de estar 
en el espacio, de los hábitos a través de los cuales el espacio mismo devenía reconocido y reconocible y ello atañe, en un primer momento y de un modo determinante, al espacio habitado y sentido de la propia corporalidad: la tortura despoja al cuerpo de su capa de hábitos para arrojarlo al torturador como mera materia biológica con la que se puede experimentar la producción de daño.

Conviene subrayar esto ya que ahí está el núcleo de la tortura, en el momento en que los hábitos que trenzan una forma de vivir, de ser, de estar, se diluyen en la violencia que la captura inaugura. El lenguaje se trunca, se impone el silencio (con el aislamiento), el grito (con el golpe), la culpabilidad (con la perversión de hacer responsable al torturado de la propia tortura que sufre) y el cuerpo, por su parte, se desfigura, se retuerce, acaso por la violencia física que recibe, pero también por el propio desgajamiento del mundo que la tortura puede imponer mediante las técnicas, por ejemplo, de la privación sensorial: no es preciso tocar el cuerpo pero sí es preciso para hablar de tortura de capturar - en el sentido que aquí se le está dando - la corporalidad y sustraerla de hábitos y hábitats, deshacerla para confrontarla desnuda frente a lo que el poder pudiera disponer con ese cuerpo inerme. El espacio vital que se deshace se recompone como una geografía político-punitiva del sufrimiento que se torna inhabitable porque se compone e impone para negar la vida misma, cualquier asomo de vida con sentido, vivible, reconocible: la tortura produce cuerpos sin mundos que transitan por la siniestra geografía político-punitiva de lo inhabitable (Mendiola, 2014).

Al margen de las técnicas empleadas (Rejali, 2007), de los distintos contenidos que se vehiculan en las violencias simbólicas y que pudieran adaptarse a la trama de hábitos que componen la subjetividad con el fin de quebrarla, la inhabitabilidad que signa la tortura responde a una práctica que atenta contra la vida, pero con la peculiaridad de que (a menudo) quiere mantener con vida a la vida, tal y como se evidencia con rotundidad con las técnicas de alimentación forzosa (Wilcox, 2015). Y así, la captura inaugurada por la tortura se precipita hacia la negación más radical de la vida, aquella que atenta contra sus fundamentos ontológicos toda vez que lo humano, su corporalidad, se asienta en una apertura en la que se precisa de los otros para sostener la vida. 
La vulnerabilidad (Butler, 2006; Cavarero, 2009), lejos de responder a una específica circunstancia sociohistórica hunde sus raíces en esa condición ontológica de lo humano que ubica al otro, a la trama de cuidados, como condición inexcusable de un vivir que es siempre un con-vivir. La tortura se asienta precisamente en esa apertura, en la herida (el vulnus) que nos abre al otro, pero de un modo tal que se despliega como una erradicación radical del cuidado con lo que la apertura queda desplegada en su propia exposición al margen de cualquier asomo de ayuda, acometiendo así aquello que está en el núcleo mismo de la tortura, lo que sienta su especificidad, esto es, un ensañamiento en la vulnerabilidad de lo humano, la producción de un sufrimiento refractario a la empatía.

La tortura produce en consecuencia una corporalidad marcada por una exposición desnuda, una apertura que carece de refugio. El relato de Jean Amery, alude con suma claridad a esta cuestión:

El primer golpe hace consciente al prisionero de su desamparo - y ya contiene en germen cuanto sufrirá más tarde (...) Se creen autorizados a golpearme el rostro, reconoce la víctima con sorda sorpresa y con certeza igual de indistinta concluye: harán conmigo lo que se les antoje (Amery, 2001:90).

En la tortura no hay refugio, sólo exposición, la sustracción de hábitos y hábitats, la conformación de una geografía de dolor marcada por la indefensión, la producción de una corporalidad doliente que lo ocupa todo. Y, por ello, lo que ahí se suscita es ajeno a una cuestión de gradiente del dolor causado. Es obvio que hay distintas intensidades en la tortura, que no es lo mismo la práctica misma que el miedo infligido anunciando lo que se puede hacer con el cuerpo (y el miedo, en numerosos relatos, aparece de forma reiterada como uno de los componentes más crueles de la tortura) pero, al margen de ello, lo que aquí se está proponiendo es vincular la tortura a la situación que origina, el escenario de una corporalidad expuesta e inerme que, mediante los distintos tipos de captura desplegados, se precipita a una inhabitabilidad que no quiere ser vivida.

El que está cogido, lo decía Canetti al hilo de la reflexión que abría el anterior epígrafe, está ya sobrecogido, esperando el envite de la violencia, carente de amparo, expuesto, abandonado, habitando en una inclusión que le excluye de un mínimo reconocimiento de su humanidad. 
Aspectos todos ellos que acontecen en un plano que no es susceptible de ser posicionado en una escala de dolor. Algo a lo que remite de un modo certero Coetzee en su novela Esperando a los bárbaros:

Pero a mis torturadores no les interesaban los distintos grados de dolor. Únicamente les interesaba demostrar lo que significa vivir en un cuerpo, solo como un cuerpo, un cuerpo que puede abrigar ideas de justicia solo mientras esté ileso y en buen estado, y que las olvida tan pronto como le sujetan la cabeza y le meten un tubo por la garganta y echan por él litros de agua salada hasta que tose y tiene arcadas y sufre convulsiones y se vacía. No vinieron para sacarme a la fuerza el relato de lo que les había dicho a los bárbaros ni de lo que los bárbaros me dijeron a mí. Por tanto, no tuve ocasión de espetarles a la cara las palabras altisonantes que tenía preparadas. Vinieron a mi celda para enseñarme el significado de la palabra "humanidad", y me enseñaron mucho en el espacio de una hora (2003:169).

\section{La dimensión de la otredad}

La definición de tortura que estamos articulando remite entonces, en su carácter procedimental, a una captura que se precipita hacia lo inhabitable. Pero este planteamiento, para tener una visión más completa de lo que ahí acontece y de sus condiciones de posibilidad, requiere aludir a una última dimensión. Un elemento que permite contextualizar el quehacer mismo de la captura en la producción de un cuerpo marcado por el dolor y la radical ausencia de cuidado. Esta cuestión que nos permite concluir el análisis sobre el concepto de tortura puede enunciarse sucintamente: para que a una persona se le inflija una tortura tiene que encarnar una subjetividad torturable. Dicho con otras palabras: no se le tortura a cualquiera, no todos estamos ubicados en unas lógicas de reconocimientos semejantes que habrían de establecer las mismas posibilidades para pasar a habitar la geografía políticopunitiva de lo inhabitable. La persona torturada ya viene envuelta en una trama narrativa que actúa a modo de cortocircuito de la empatía ubicándola en un fondo de desprecio que imposibilita actuar cuando el sufrimiento tiene lugar.

Sofsky ha expresado esta cuestión con rotundidad: "La tortura traza una línea de demarcación entre amigos, enemigos y extranjeros, entre ciudadanos y bárbaros, civilizados y salvajes, fieles e infieles. Y separa a los hombres de los no-hombres" (2006:87). La persona torturada no sólo ha sido capturada, arrancada de su cotidianidad y puesta contra 
su voluntad en lo inhabitable sino que también queda ubicada, por retomar la clásica distinción de Schmitt entre amigo y enemigo, en una enemistad irreconducible, una no-persona (Dal Lago, 2005) que le convierte en alguien ajeno al ciudadano, alguien que, por aquello que encarna, permite que el sufrimiento se despliegue porque ahí no hay una persona que merezca ser cuidada cuanto el cuerpo de un no-hombre signado por el desprecio. Igualmente, en su fundamental análisis de la tortura en la Grecia clásica, DuBois alude a esta misma cuestión cuando afirma lo siguiente:

El torturado puede ser negro, comunista, revolucionario, gay, pero la tortura reduce la particularidad de la diferencia, de la otredad, al hecho de ser torturado. Todos los que son torturados son sumidos en la otredad, convertidos en esclavos para el torturador-dueño. Esto es lo que podríamos llamar el sentido interno del diálogo entre el torturado y el torturador, las identidades jerárquicas establecidas entre el uno y el otro (1991:153).

En este sentido, la historia de la tortura (Mellor, 1968; Peters, 1987) puede trazarse a modo de una historia de la torturabilidad, de las construcciones narrativas que van articulando, en cada momento histórico y geográfico, el semblante de aquellas subjetividades que entran a formar parte del caleidoscopio heterogéneo de la enemistad, del otro-despreciable. Del mismo modo en que el sufrimiento es una realidad que mira tanto al sujeto que lo padece como a las lógicas sociales que producen dicho sufrimiento, la categoría de la otredad da rostro a aquellas subjetividades concretas que emergen en la diferencia, nombra sus peculiaridades, el modo en que son categorizadas, pero para su correcta comprensión ello requiere remontarnos a esas lógicas sociales que han posibilitado la irrupción de una otredad concreta: la producción del otro requiere indagar en su sociogénesis, en los procesos sociohistóricos de diverso signo que, en última instancia, se materializan en esa persona concreta capturada que experimenta en la inmediatez de su piel la violencia ilimitada de lo inhabitable.

No es posible establecer aquí con detalle desarrollos concretos en torno a la producción concreta de otredades, algo además que lógicamente adquiere expresiones diversas en función de las características específicas de cada contexto geográfico, pero sí cabría al menos pergeñar, a modo de marco genérico, esas otredades que si atendemos a numerosos informes de agencias internacionales concernidas con esta temática, tienden a quedar reflejadas en las denuncias que se realizan por casos 
de tortura en los países occidentales. En ese marco genérico irrumpen las actuales subjetividades torturables que podemos categorizar bajo la rúbrica de las otredades de la amenaza y de la exclusión. Si bien podríamos decir que la otredad de la amenaza se proyecta sobre aquellos sujetos que pueden suponer un atentado directo contra la vida misma mientras que, por su parte, la otredad de la exclusión alude a otras subjetividades que pueden venir a socavar un estilo de vida, esta distinción, más que aludir a una dicotomía nítida de compartimentos estancos, opera a modo de un cuadro genérico en donde la exclusión y la amenaza son susceptibles de solaparse con intensidades variables.

Así las cosas, por una parte, en el polo de la amenaza, la figura que sobresale es la del terrorista pero siendo ya esta una figura sin límites claros en donde el propio hacer y decir securitario ha terminado por ensanchar sus límites de un modo tal que la antes mencionada distinción de Schmitt entre amigo y enemigo se quiebra en el intersticio mismo de la dicotomía al irrumpir el sesgo de la sospecha: el terrorista fehaciente se transmuta en el sospechoso de ser terrorista. Por otra parte, en la otredad de la exclusión nos encontramos con el sujeto migrante que no pretende atentar contra la vida misma cuanto buscar una oportunidad vital en otras geografías pero este mismo desplazamiento es leído como un potencial quebrantamiento de un estilo de vida que hay que salvaguardar. Las figuras del otro-terrorista y del otro-migrante se convierten así en las dos grandes ejemplificaciones de una otredad carente de reconocimiento, cada una con sus propias características, pero unidas por un discurso securitario que detecta riesgos de distinto signo y articula respuestas violentas ante la presencia de esas subjetividades susceptibles de ser capturadas y arrojadas a lo inhabitable, no tanto por lo que pudieran haber hecho como por la propia subjetividad que encarnan.

El otro-terrorista será rastreado, capturado y eventualmente torturado en toda una geografía dispersa e (in)formal de privación de libertad; el otro-migrante será igualmente rastreado, capturado y eventualmente torturado en los intentos por acometer el cruce fronterizo, en sus detenciones en centros de internamiento o en las distintas prácticas de expulsión y deportación a las que se ve sometido. El auge del discurso securitario que tiene lugar en el marco de la llamada guerra contra el terror vendrá a configurar todo un contexto político-jurídico que favorece una retórica y una práctica de la excepcionalidad que si bien se proyecta en un primer momento sobre el otro-terrorista acaba, en 
las mutaciones a las que se ve sometido, por impregnar las políticas de control migratorio dando lugar así a toda una deriva de criminalización del migrante (Nail, 2016). En este escenario en donde la dimensión jurídico-política de respuesta a la amenaza terrorista se solapa con la dimensión socio-económica para gestionar la exclusión del migrante nos encontramos con situaciones diversas que emanan, sin embargo, de un sustrato crecientemente compartido que se teje con las formas de hacer y pensar securitarias.

Por último, cabría igualmente aludir, para completar esta somera radiografía de la torturabilidad a dos situaciones que remiten, por una parte, al contexto de la movilización propia de la protesta política, entendida esta como una amenaza al orden policial en el sentido que Rancière (1996) da este término; aquí nos encontramos con una subjetividad que puede ser ciertamente diversa pero que por el posicionamiento que ocupa en tanto que participe de una protesta política puede acabar siendo objeto de una violencia policial que actúa, desde ese discurso securitario, como garante del restablecimiento de una convivencia normalizada. Y, por otra, habría que hacer alusión a un segmento de la población reclusa subsumida en un contexto de opacidad social, institucional y mediática que favorece todo un clima de violencia simbólica y física que se ve incrementado, como antes se sugería, en los regímenes punitivos de aislamiento. La protesta política opera en el polo de una amenaza (aunque esta sea no violenta) al orden sociopolítico mientras que la población reclusa susceptible de ser torturada en mayor medida habita en el polo de una exclusión socioeconómica. Figuras disímiles que incorporan en distinto grado connotaciones de amenaza y exclusión posibilitando así, en última instancia, el despliegue de una violencia proyectada sobre sus cuerpos.

Más allá de las subjetividades de la otredad concretas que emergen en cada contexto sociohistórico específico, la relevancia de esta dimensión nos obliga a levantar la mirada del hacer intencional de un torturador para reubicar el desprecio hacia la persona torturada en el marco de una narrativa de corte más contextual desde la que se definen aquellas subjetividades no reconocidas. El torturador es siempre el pliegue de un contexto político-punitivo que tiene sus propias normas de funcionamiento, sus hábitos, sus relaciones de poder y sus narrativas y, en ese sentido, una vez más, deviene necesario reasentar cada práctica concreta de tortura en el contexto de una producción social de la tortura en los distintos niveles en los que esta tiene lugar. 


\section{CONCLUSIÓN}

Desde el análisis de las carencias detectadas en la definición contenida en el texto de la Convención contra la tortura y otros tratos o penas crueles, inhumanos o degradantes, auspiciada por las Naciones Unidas, y que en gran parte vienen asociadas a una lectura crítica de las nociones de intencionalidad y gravedad, nos hemos acercado a una propuesta conceptual por medio de la cual la realidad específica de la tortura emerge como una captura vinculada a un entramado estatal que produce contextos de inhabitabilidad en subjetividades inferiorizadas inmersas en lógicas de desprecio. De un modo sucinto, y recogiendo las tres dimensiones sobre las que se ha construido esta propuesta, podríamos concluir sugiriendo que la tortura es una negación radical del cuidado, un ensañamiento en la vulnerabilidad de lo humano (dimensión de lo inhabitable), cuyas condiciones de posibilidad están imbricadas tanto con el hacer como con el dejar hacer de determinados sujetos o instancias asociadas de un modo u otro al ámbito públicoestatal (dimensión de la captura) y que se proyectan mayormente sobre subjetividades inmersas en narrativas de amenaza y exclusión que socavan el reconocimiento de esas subjetividades, al tiempo que niegan una empatía que habría de cortocircuitar el dolor y sufrimiento causado (dimensión de la otredad).

Tal y como se sugirió en la introducción esta aproximación tiene una clara orientación analítica y conceptual para repensar lo que entendemos por tortura. Pero también tiene una proyección ético-política que es preciso no desdeñar porque, tal y como se ha sugerido en las líneas precedentes, la reflexión sobre la tortura lejos de ser el análisis de un acto puntual, nos confronta con una práctica político-punitiva que perviveen contextos sociales que se narran bajo las categorías de desarrollo, democracia o progreso. La tortura no está sólo en un pasado carente de civilización ni en una dictadura militar sustentado en una violencia ilegítima, como si fuera un problema que ya no nos atañe (Kelly, 2012); también está, desigualmente y no necesariamente subsumida en prácticas sistemáticas, en las democracias occidentales u occidentalizadas, allí donde supuestamente no cabría encontrar atisbos de su presencia. Ciertamente, la relación de la modernidad con la tortura en modo alguno puede leerse como una creciente racionalización que habría de dejar atrás la barbarie contenida en la tortura 
(Asad, 2011); más bien habría que hablar de una relación intrincada y paradójica con la tortura que está mediada por la espacialidad en la que se aplica y por las subjetividades sobre las que se proyecta.

Lo que me interesa resaltar para concluir es que esa relación se nos presenta en la actualidad, de un modo más acuciante, bajo el influjo de un hacer y decir securitario que se despliega coaligado con toda una trama de violencias simbólicas y materiales. Desde este prisma, confrontarnos analíticamente con la tortura se precipita, en última instancia (algo que aquí sólo ha podido sugerirse y apuntarse), con esa deriva ético-política que problematiza el régimen de verdad securitario en el que estamos inmersos con el fin último de socavar la propia perpetuación de la violencia infligida. Las aportaciones de autores como Fassin (2018) sobre una economía moral leída en clave política, de Santos (2005) sobre las imágenes desestabilizadoras en las que leer críticamente la producción de sufrimiento, de Didi-Huberman (2014) sobre los acontecimientos sensibles a través de los cuales habríamos de repensarnos ante un dolor que "nos mira y nos concierne directamente", designan acercamientos necesarios a través de los cuales ahondamos en la producción de la violencia que forma parte de los hábitats que habitamos.

La crítica incondicional de la tortura no pasa únicamente por el establecimiento de todo un conjunto de medidas que en su propio ejercicio vendrían a socavar el ejercicio de este castigo; en un sentido más profundo pasa por una exigencia ético-política que niega radicalmente la animalización de lo humano, la reducción del otro, sea quien sea, a una corporalidad despreciable en la que cabe infligir dolor y sufrimiento. En la apertura que sugiere Rancière (1996) hacia otra redistribución de lo sensible cuando la subjetivación política se inicia como proceso crítico de la habitualidad en la que estamos inmersos, en ese proceso que introduce otras narrativas desde las que leer aquello que (nos) pasa, la crítica incondicional de la violencia securitaria banalizada se impone como requisito ineludible.

(Recebido para publicação em 22 de outubro de 2018)

(Reapresentado em 19 de abril de 2019)

(Aprovado para publicação em 14 de junho de 2019) 


\section{REFERÊNCIAS}

AGAMBEN, Giorgio. (1998), Homo Sacer. El poder soberano y la nuda vida. Valencia: Pre-Textos.

AGIER, Michel. (2015), Zonas de frontera. La antropología frente a la trampa identitaria. Rosario, Editorial de la Universidad Nacional de Rosario.

AVELAR, Idelbar. (2004), The letter of violence. Essays on narrative, ethics and politics. New York: Palgrave Macmillan.

ASAD, Talal. (2011), "Reflexões sobre crueldade e tortura”. Revista Pensata, v. 1, n. 1, pp. 164-187.

BALZACQ, Thierry et al. (2010), “Security Practices". In: R. A. Denemark; R. Marlin-Bennett (eds.), International Studies Encyclopedia Online. Wiley-Blackwell, pp. 1-30.

BIGO, Didier. (2008), "Globalized (in)security: the field and the ban-opticon". In: D. Bigo; A. Tsoukala (eds.), Terror insecurity and liberty. Iliberal practices of liberal regimes after 9/11. London: Routledge.

BENJAMIN, Walter. (1991), Para una crítica de la violencia y otros ensayos. Madrid: Taurus.

BURGERS, J. Herman; y DANELIUS, Hans (1988), The United Nations Convention against Torture. A handbook on the Convention against Torture and other Cruel, Inhuman or Degrading Treatment or Punisment. Dordrecht, Martinus Nijhoff Publishers.

BUTLER, Judith. (2006), Vida precaria. Buenos Aires, Paidós.

CALVEIRO, Pilar. (2010), "El vaciamiento de los cuerpos. El encierro en México". In M. Aguiluz Ibargüen; P. Briones Lazo (eds.), Corporalidades. México D.F.: UNAM.

CANETTI, Elias. (1987), Masa y poder. Madrid: Alianza Editorial.

CAVARERO, Adriana. (2009), Horrorismo. Nombrando la violencia contemporánea. Barcelona: Anthropos.

DAL LAGO, Alexandro. (2005), “La guerra-mundo”. In: R. Bergalli y I. Rivera (ed.), Política criminal de la guerra. Barcelona: Anthropos.

DAS, Veena. (2008), “La antropología del dolor". In: F. A. Ortega (ed.), Veena Das. Sujetos del dolor. Agentes de dignidad. Bogotá: Universidad Nacional de Colombia.

DAYAN, Colin. (2007), The story of cruel and unusual. Cambridge: MIT Press.

DELEUZE, Gilles y GUATTARI, Félix. (1988), Mil mesetas. Valencia: Pre-Textos.

. (1997), ¿Qué es la filosofía? Barcelona: Anagrama.

DE LA CUESTA AZURMENDI, José Luis. (1990), El delito de tortura. Barcelona: Bosch Casa Editorial.

DIDI-HUBERMAN, Georges. (2014), “Volver sensible/Hacer sensible”. In: A. Badiou et al. (eds.), ¿Qué es un pueblo? Madrid: Casus Belli.

ESPOSITO, Roberto. (2005), Immunitas. Protección y negación de la vida. Buenos Aires: Amorrortu.

FASSIN, Didier. (2018), Por una repolitización del mundo. Las vidas descartables como desafío del siglo XXI. Buenos Aires: Siglo XXI. 


\section{Ignacio Mendiola}

FELDMAN, Allen. (2004), "Securocratic wars of public safety. Globalized policing as scopic regime”. Interventions, v. 6, n. 3, pp. 330-350.

FOUCAULT, Michel. (2001), “El sujeto y el poder”. In B. Wallis (ed.), Arte después de la modernidad. Nuevos planteamientos en torno a la representación. Madrid: Akal.

GARLAND, David. (2013), Una institución particular. La pena de muerte en Estados Unidos en la era de la abolición. Buenos Aires: Didot.

KELLY, Tobias. (2012), This side of silence. Human rights, torture and the recognition of cruelty. Philadelphia: University of Pennsylvania Press.

LAURIE, Emma W.; SHAW, Ian G.R. (2018), "Violent conditions: the injustices of being". Political Geography, v. 65, pp. 8-16.

MÉNDEZ, Juan E. (2011), “Informe del Relator Especial sobre la tortura y otros tratos o penas crueles, inhumanos o degradantes. Disponible en http:/ / www.ppn.gov.ar/sites / default/files/Informe\%20Rel.\%20Tort.-Confinamiento-2011.pdf. Accedido el 4 de jul. 2018.

. (2013), "Informe del Relator Especial sobre la tortura y otros tratos o penas crueles, inhumanos o degradantes". Disponible en https: / www.ohchr.org/Documents/HRBodies/HRCouncil/RegularSession/Session22/A-HRC-22-53_sp.pdf

MENDIOLA, Ignacio. (2014), Habitar lo inhabitable. La práctica político-punitiva de la tortura. Barcelona: Bellaterra.

MELLOR, Alec. (1968), La tortura. Barcelona: Editorial Estela.

NAIL, Thomas. (2016), "A tale of two crises: migration and terrorism after the Paris attacks". Studies in Ethnicity and Nationalism, v. 16, n. 1, pp. 158-167.

NEOCLEOUS, Mark. (2014), War power, police power. Edimburgo: Edinburgh University Press.

NIETZSCHE, Friederich. (1981), La genealogía de la moral. Madrid: Alianza.

NOWAK, Manfred. (2009), "Informe del Relator Especial sobre la tortura y otros tratos o penas crueles, inhumanos o degradantes". Disponible en https: / / documents-dds-ny. un.org/doc/UNDOC/GEN/G09/103/15/PDF/G0910315.pdf?OpenElement. Accedido el 10 de jul. 2018.

ONG, Aihwa. (2010), Neoliberalism as exception: mutations in citizenship and sovereignty. Durham: Duke University Press.

PALMA, Mauro. (2010), “El control del Comité europeo para la prevención de la tortura sobre la privación de libertad por parte de la autoridad pública". In: C. Fernández Besa et al. (eds.), Contornos bélicos del Estado securitario. Barcelona: Anthropos.

PARRY, John T. (2010), Understanding torture: law, culture and state violence. Michigan: University of Michigan Press.

PETERS, Edward. (1987), La tortura. Madrid: Alianza.

HELLER, Charles; PEZZANI, Lorenzo. (2014), "Liquid traces: investigating the deaths of migrants at the EU's Maritime Frontier. In: Forensis: The Architecture of Public Truth. Berlin, Sternberg Press, pp. 657-684. 
PORTILLA, Guillermo. (2009), “El regreso del concepto de seguridad del estado como bien jurídico autónomo y una consecuencia: la participación de los gobiernos europeos en las detenciones ilegales y torturas practicadas por funcionarios de EEUU". Anales de la Cátedra Francisco Suárez, n. 43, pp. 93-115.

RANCIÈRE, Jacques. (1996), El desacuerdo. Política y filosofía. Buenos Aires: Nueva Visión.

REDRESS y Amnistía Internacional (2011), "Gender and torture. Conference report". [2005-2018]. Disponible en http://www.redress.org/downloads/publications/GenderandTortureConferenceReport-191011.pdf

REJALI, Darius. (2007), Torture and democracy. Princeton: Princeton University Press.

RIOS, Julián C.; CABRERA, Pedro J. (2002), Mirando el abismo. El régimen cerrado. Madrid: Universidad Pontificia Comillas.

RIVERA, Iñaki. (2006),'La impunidad de la tortura y las obligaciones de los Estados en el marco institucional y estatal". In: R. Bergalli; I. Rivera (eds.), Torturas y abuso de poder. Barcelona: Anthropos.

SANTOS, Boaventura de Sousa. (2005), El milenio huérfano. Ensayos para una nueva cultura política. Madrid: Trotta.

SCARRY, Elaine. (1985), The body in pain. The making and unmaking of the world. Oxford: Oxford University Press.

SCHEPER-HUGHES, Nancy; BOURGOIS, Philippe (eds.). (2004), Violence in war and peace. An anthology. Oxford: Blackwell.

SHAW, Ian. (2016), Predator empire. Drone warfare and full spectrum dominance. Minneapolis: University of Minnesota Press.

SOFSKY, Wolfgang. (2006), Tratado sobre la violencia. Madrid: Abada.

WILCOX, Lauren. (2015), Bodies of violence. Theorizing Embodied Subjects in International Relations. Oxford: Oxford University Press.

WISNEWSKI, Jeremy J. (2010), Understanding torture. Edimburgo: Edinburgh University Press.

WOOLGAR, Steve. (1991), Ciencia: Abriendo la caja negra. Barcelona: Anthropos.

ZIZEK, Slavoj. (2009), Sobre la violencia. Seis reflexiones marginales. Buenos Aires: Paidós. 


\section{RESUMO}

Em Torno na Definição de Tortura: A Necessidade e Dificuldade de Conceituar a Produção Ilimitada de Sofrimento

A definição da tortura está longe de ser uma questão simples que poderia se delimitar com clareza pela diferença desta prática punitiva em relação a outro tipo de punições. Os limites da tortura podem ser certamente esquivos em seu exercício por uma desestruturação radical do humano. Para abordar esta questão, este artigo entra neste assunto da caracterização da tortura por meio de um plano duplo. Por uma parte, far-se-á uma leitura crítica da definição mais empregada e que está contida no texto da Convenção contra a tortura e outros tratamentos ou penas cruéis, desumanos ou degradantes, promovida pelas Nações Unidas. Por outro lado, articular-se-á uma proposta de definição construída a partir de três dimensões interconectadas que remetem a captura (vinculada direta ou indiretamente à estrutura público-estatal), ao inabitável (referida à produção de um corpo sofredor sem proteção) e à alteridade (relacionada com as subjetividades não reconhecidas sobre as quais se projeta).

Palavras-chave: tortura; corpo; violência; subjetividade; estado

\section{ABSTRACT \\ On the Definition of Torture: The Necessity and Difficulty of Conceptualizing the Unlimited Production of Suffering}

The definition of torture is far from a simple matter that could be clearly delimited through the difference between this punitive practice and other types of punishment. The limits of torture can certainly be elusive in their pursuit of a radical disruption of the human. To address this issue, this article focuses on the subject of characterizing torture through a dual plan. On the one hand, a critical reading of the most commonly used definition, contained in the text of the Convention against torture and other cruel, inhuman or degrading treatment or punishment, will be taken. On the other hand, we will articulate a definition proposal built from three interconnected dimensions that refer to capture (linked directly or indirectly to the public-state structure), uninhabitable (referred to the production of a suffering body without protection) and alterity (related with the unrecognized subjectivities it is projected upon).

Keywords: torture; body; violence; subjectivity; state 


\section{RÉSUMÉ}

Autour de la Définition de la Torture: Nécessité et Difficulté de Conceptualiser la Production Illimitée de Souffrance

La définition de la torture est loin d'être une question simple qui pourrait être clairement délimitée par la différence de cette pratique punitive avec d'autres types de sanctions. Les limites de la torture peuvent certainement être insaisissables dans leur exercice par une perturbation radicale de l'Humain. Pour résoudre ce problème, cet article aborde cette question de caractériser la torture à travers un double plan. D'une part, une lecture critique de la définition la plus couramment utilisée contenue dans le texte de la Convention des Nations Unies contre la torture et autres peines ou traitements cruels, inhumains ou dégradants sera effectuée. D'autre part, une proposition de définition sera articulée sur la base de trois dimensions interconnectées qui se réfèrent à la capture (liée directement ou indirectement à la structure de l'État public), à l'inhabitable (se réfère à la production d'un corps souffrant sans protection) et à l'altérité (liée aux subjectivités non reconnues sur lesquelles elle est projetée).

Mots-clés: torture; corps; violence; subjectivité; l'état

\section{RESUMEN}

En Torno a la Definición de Tortura: la Necesidad y Dificultad de Conceptualizar La Producción Ilimitada De Sufrimiento

La definición de la tortura dista mucho de ser una cuestión sencilla a través de la cual se podría delimitar con nitidez por la diferencia de esta práctica punitiva con respecto a otro tipo de castigos. Los límites de la tortura pueden ser ciertamente esquivos en su ejercicio por acometer una desestructuración radical de lo humano. Para abordar esta cuestión, este artículo se adentra en este terreno de la caracterización de la tortura a través de un doble plano. Por una parte, se realizará una lectura crítica de la definición más empleada y que está contenida en el texto de la Convención contra la tortura y otros tratos o penas crueles, inhumanos o degradantes promovida por las Naciones Unidas. Por otro lado, se articulará una propuesta de definición construida a partir de tres dimensiones interconectadas que remiten a la captura (ligada de un modo directo o indirecto al entramado público-estatal), a lo inhabitable (referida a la producción de un cuerpo doliente sin protección) y a la otredad (concernida con las subjetividades no reconocidas sobre las que se proyecta).

Palabras clave: tortura; cuerpo; violencia; subjetividad; estado 